\title{
Limits to the Strength Design of Reinforced Concrete Shells and Slabs
}

Enrique Hernández-Montes ${ }^{1}$, Juan F. Carbonell-Márquez ${ }^{2}$ and Luisa. M. Gil-Martín ${ }^{3}$

(Published in “Engineering Structures”, Volume 61, March 2014, Pages 184-194)

\section{http://dx.doi.org/10.1016/j.engstruct.2014.01.011}

\begin{abstract}
One of the most important works in the ultimate limit state design of reinforced concrete plates or shells subjected to flexure and membrane actions is the one provided by Brondum-Nielsen (Brondum-Nielsen, 1974). Therein, the author divides the shell element into three layers; the outer layers withstand a state of membrane forces located on their middle surfaces. The forces at the centroid of the reinforcement, in both directions, have been obtained from equilibrium, and the steel area needed is computed by dividing these tension forces by the steel yield stress, $f_{y}$. An extension to the strain plane hypothesis widely used in the strength design of RC beams and columns is presented, aiming at RC strength design of shells and slabs. As a result, limits to the application of the Bromdum-Nielsen procedure are given in this work since it cannot always be guaranteed that the stress in the steel is $f_{y}$ as the original method proposes. A new method based on the computation of the balance point in the beam flexure design is developed to check the limits of application of Brondum-Nielsen's approach. The Upper Bound Theorem of plasticity guaranties that the obtained forces are on the safe side. Examples are provided.
\end{abstract}

\footnotetext{
${ }^{1}$ Professor, Department of Structural Mechanics, University of Granada (UGR). Campus Universitario de Fuentenueva s/n. 18072 Granada, Spain. emontes@ugr.es.

2 PhD Candidate, Department of Structural Mechanics, University of Granada (UGR). Campus Universitario de Fuentenueva s/n. 18072 Granada, Spain. (corresponding author). Email jfcarbonell@ugr.es. Tel.: +34 958249965; fax: +34 958249959

${ }^{3}$ Associate Professor, Department of Structural Mechanics, University of Granada (UGR). Campus Universitario de Fuentenueva s/n.18072 Granada, Spain. mlgil@ugr.es.
} 
KEYWORDS: Reinforced Concrete; Shell; Slab; Optimization; Balance point;

\section{Notation}

$a$

$a_{b}, a_{t}$

$c_{b}, C_{t}$

$c_{b 0}$

$C_{\text {kilim }}$

$d$

$f_{c}$

$f_{y}$

$E_{s}$

$e_{k}$

$h$

$z_{y a}$

$Z_{y a t}$

$Z_{y a b}$

$z_{x a}, z_{x a t}, z_{x a b}$

$M_{a}$

$M_{x}, M_{y}$

$M_{x y}$

$N$

$N_{x}, N_{y}$

$N_{x y}$

$N_{x k}, N_{y k}$

$N_{x y k}$

$N_{x a k}, N_{y a k}$
Distance between the middle surfaces of the top and bottom layers

Distances between the middle surfaces of bottom and top layers to the middle surface

of the shell, respectively

Depth of bottom and top layers , respectively

First approximation of $c_{b}$

Limit depth of layer $k$ ( $k=t$ for top layer; $k=b$ for bottom layer) in order to yield the reinforcement in $i$ direction ( $x$ or $y$ ) placed in the opposite layer $j$

depth of the reinforcement

Concrete compression strength

Yield stress of the reinforcement

Young's modulus of the steel

Distance between the middle layer of the shell element to the centroid of the reinforcement placed in layer $k$

Depth of the shell element

Lever arm of $N_{y a t}+N_{y a b}$ related to the centre of gravity of the gross section

Lever arm of $N_{\text {yat }}$ related to the centre of gravity of the gross section

Lever arm of $N_{y a b}$ related to the centre of gravity of the gross section

Idem for $N_{x a t}+N_{x a b}, N_{x a t}$ and $N_{x a b}$.

Flexural moment considered for the first estimation of $c_{b}$

Bending moments in $x$ and $y$ directions applied to the shell element

Twisting moment applied to the shell element

Axial force

Normal forces in $x$ and $y$ directions applied to the shell element

Shear force applied to the shell element

Membrane normal forces in $x$ and $y$ directions in layer $k$

Membrane shear force in layer $k$

Tension forces in reinforcement placed in $x$ and $y$ directions in layer $k$ 


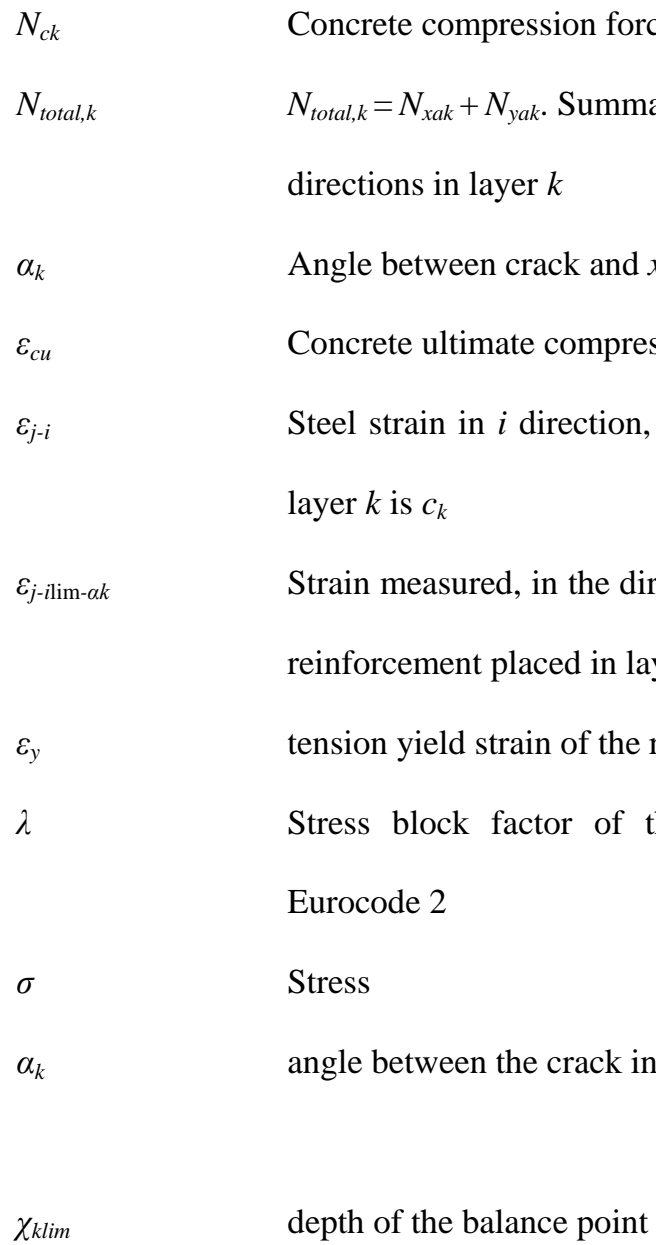

$\underline{\text { Subscript }}$

$a$

$b$

i

j

$k$

$x$

$\lim$

y

$\underline{\text { Superscript }}$

* actual value

\section{Introduction}


Capacity of reinforced concrete (RC) shells and slabs has always been an interesting topic, e.g. [1][2][3]. The problem of designing the reinforcement for a concrete plate or shell in ultimate limit state to withstand membrane forces together with bending and torsion moments has not yet been universally solved. As a consequence, the main RC design codes - Eurocode 2 [4], AC1 318 [5] - do not provide a general method to deal with this problem as they do with the beam cross section design. Only the Model Code CEB-FIP 2010 (MC2010) [6] states, literally, that "shell elements may be modelled as comprising three layers. The outer layers provide resistance to the in-plane effects of both the bending and the in-plane axial loading, while the inner layer provides a shear transfer between the outer layers.” But the designer would have difficulty finding further information on this issue.

You can find many different techniques in literature that try to obtain a generally accepted solution. One of the first practical approaches to this problem is the report by Brondum-Nielsen [7]. This work deals with the shell element as if it were a sandwich element composed of three layers, with the outer layers being responsible for withstanding the membrane force decomposition of the external bending, torsion, in-plane axial and in-plane shear loading. Each of these layers contains an orthogonal reinforcing net. Gupta [8] takes the work of BrondumNielsen as a reference to propose a general solution based on an iterative trial-and-error design method using the principle of minimum resistance by also dividing the shell into three layers containing the orthogonally provided reinforcement. Marti [9] assigns the out of plane shear to the middle layer, complementing the work of Brondum-Nielsen. Lourenço and Figueiras [10] [11] formulated the problem of reinforcing elements subjected to membrane and flexural forces based on equilibrium conditions and suggested a new iterative procedure. They have developed a consistent solution to the problem analyzing the shell element as a whole and not as two membrane outer layers. The information concerning this approach has been compiled by Fall et al. [12] in their revision of procedures of reinforcing methods in RC tailor-made structures. A similar approach to the one presented by Gupta is implemented in an iterative numerical computational algorithm by Min [13] and tested in several experimental examples. Furthermore, 
nonlinear inelastic analyses are performed using the Mahmoud-Gupta's computer program [14][15][16][17] to prove the adequacy of the presented equations. A similar formulation of the problem is adopted by Tomás and Martí [18] in order to mathematically optimize the amount of reinforcement in each finite element of the mesh that models the geometry of the problem, employing the summation of the tensile forces in the reinforcement as the objective function. One of the most recent works in this field is the one proposed by Bertagnoli et al. [19] where the authors provide a method based on sandwich layers to optimize the amount of reinforcing steel to be placed in the two outer layers. The method considers non-orthogonal reinforcement layouts, and the optimization procedure is based on genetic algorithms.

It is extraordinary that, despite all the aforementioned works, one of the most powerful and popular commercial pieces of software in structural design, the SAP $2000^{\circledR}$, uses the very first of one of these methods (Brondum-Nielsen's approach) to design the reinforcement of concrete shells in ultimate limit state under bending and in-plane axial forces [20].

Apart from dividing the shell element into some layers, all the presented works have another aspect in common with respect to the stresses in the reinforcement and in the concrete. The compressive stress in concrete - compression struts - should be distributed uniformly throughout the depth of the layer and the steel in tension is assumed to be yielded, -i.e. with stress equal to $f_{y}$ - the later hypothesis is also known as limit-analysis solution. Both the tensile stress in concrete and the compressive stress in the reinforcement are neglected.

The part concerning the yielding of the reinforcement is found to be questionable by the authors of this study. Similarly, as in the case of ultimate state of bending in beams, where the plane sections hypothesis has to be satisfied, the strain in the reinforcement of one of the outer layers in a slab element should be related to the depth of the compression stress block in the opposite one.

This paper presents a necessary hypothesis to the strength design of reinforced concrete shells and slabs. Furthermore Marti [9] expresses an attempt to limit the applicability of Brondum- 
Nielsen's method “... these equations are only valid if the concrete compressive strength of the sandwich cover is not exceeded" -he calls cover to the thickness of the layer-. His attempt, although interesting, is an inaccurate observation that limits his design to small axial forces and he fails to provide a basic understanding of the behaviour of steel. Nonetheless an extension of the well established assumptions considered in the strength design of beams under bending is indeed a good advance in the reinforced concrete design of slabs and shells.

The present work draws on the formulation of the problem given in Brondum-Nielsen's procedure [7] to set the domains where this approach is valid. Firstly, Brondum-Nielsen’s method is explained in a more compact fashion and the paper is therefore self-contained. Later, the beam balance point analogy is stated in order to determine reasonable limits to the application of Brondum-Nielsen's method. Finally, the original example given in BrondumNielsen's report is explained and the limits of application are checked.

\section{Membrane forces decomposition of externally applied loads}

The concrete shell element considered in this work has to withstand the established normal forces $N_{x}$ and $N_{y}$, the shear force $N_{x y}$, the bending moments $M_{x}$ and $M_{y}$ and the twisting moment $M_{x y}$. These actions are given per unit of length. Actions are considered positive if they are directed as indicated in Fig. 1(a). The shell element has one or two parallel layers of orthogonal reinforcing net of which the position is known. The depth of the shell element is $h$.

Taking into account the state of the applied loads (Fig. 1(a)) and the geometry of the sandwich shell element (Fig. 1(b)), all forces and moments acting in the shell element may be resolved into membrane forces applied at the middle surface of top and bottom outer layers according to equilibrium equations: Eq. (1), as shown in Fig. 2. Sub-indexes $t$ and $b$ refer to the top and bottom layer, respectively. The terms $c_{t}$ and $c_{b}$ are the depth of the outer layers, $a_{t}$ and $a_{b}$ are the distances between their middle surfaces and the middle surface of the shell element and $a$ is the distance between the top and bottom middle surfaces, as indicated in Fig. 1(b). 


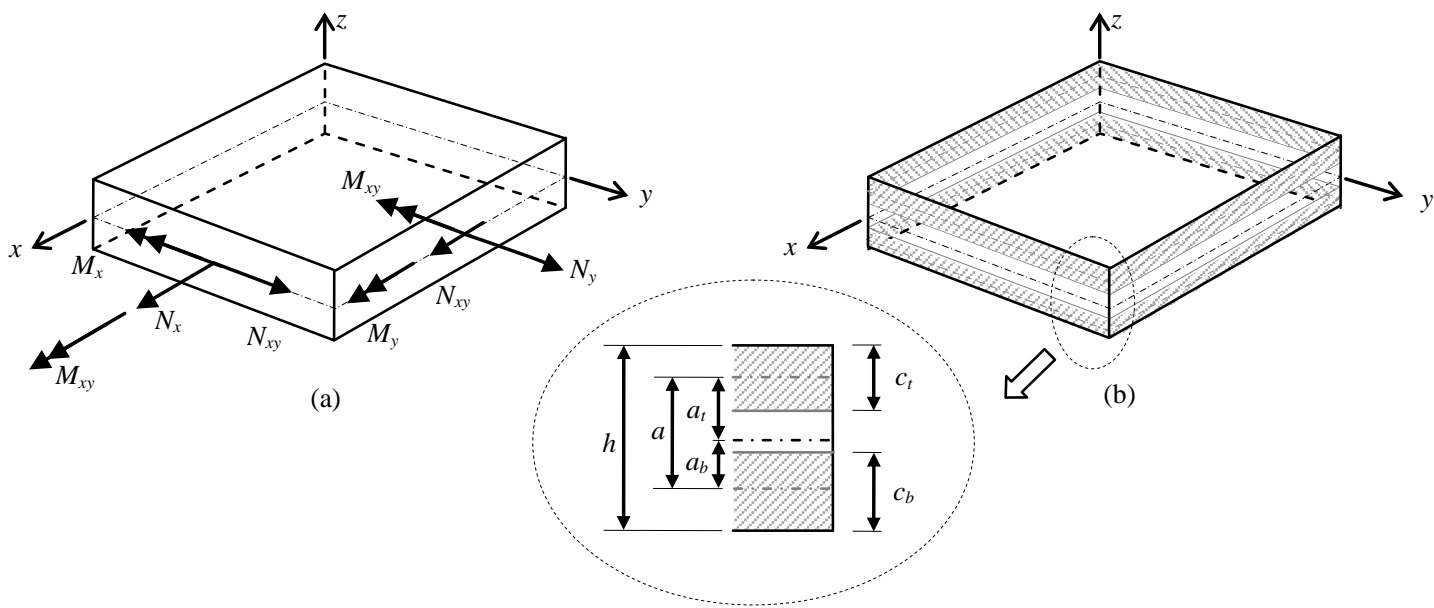

Fig. 1. (a) Applied actions to the shell element; (b) Sandwich layers geometry

$$
\begin{aligned}
N_{x t}=N_{x} \frac{a_{b}}{a}-\frac{M_{x}}{a} & N_{x b}=N_{x} \frac{a_{t}}{a}+\frac{M_{x}}{a} \\
N_{y t}=N_{y} \frac{a_{b}}{a}-\frac{M_{y}}{a} & N_{y b}=N_{y} \frac{a_{t}}{a}+\frac{M_{y}}{a} \\
N_{x y t}=N_{x y} \frac{a_{b}}{a}-\frac{M_{x y}}{a} & N_{x y b}=N_{x y} \frac{a_{t}}{a}+\frac{M_{x y}}{a}
\end{aligned}
$$

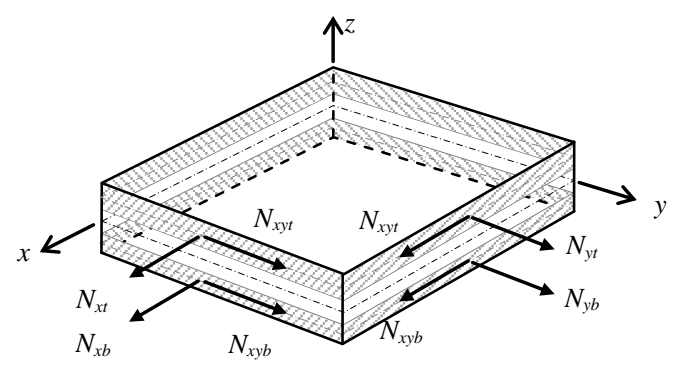

Fig. 2. Membrane forces decomposition of the state of actions applied to the shell element

\section{Limit analysis of each membrane layer}

Consider now the layer $k$ of the above sandwich element, it is cracked under the actions of the external forces, and layer $\mathrm{j}$ is the opposite outer layer. If $\mathrm{k}$ refers to top layer, then $\mathrm{k}=\mathrm{t}$ and $\mathrm{j}=$ b, and vice versa. Fig. 3 shows a portion of this layer, with two of its sides being parallel to the $x$ and $y$ directions and the third one corresponding to a crack in the membrane, which forms an angle $\alpha_{k}$ with $x$ direction. The length of this crack is taken equal to 1 .

From equilibrium in Fig. 3. (a), the forces in the reinforcement per unit of length in both $x$ and $y$ directions, $N_{x a k}$ and $N_{y a k}$, can be obtained: 


$$
\begin{aligned}
& N_{x a k} \sin \alpha_{k}=N_{x k} \sin \alpha_{k}+\left|N_{x y k}\right| \cos \alpha_{k} \rightarrow N_{x a k}=N_{x k}+\left|N_{x y k}\right| \cot \alpha_{k} \\
& N_{y a k} \cos \alpha_{k}=N_{y k} \cos \alpha_{k}+N_{x y k}\left|\sin \alpha_{k} \rightarrow N_{y a k}=N_{y k}+N_{x y k}\right| \tan \alpha_{k}
\end{aligned}
$$

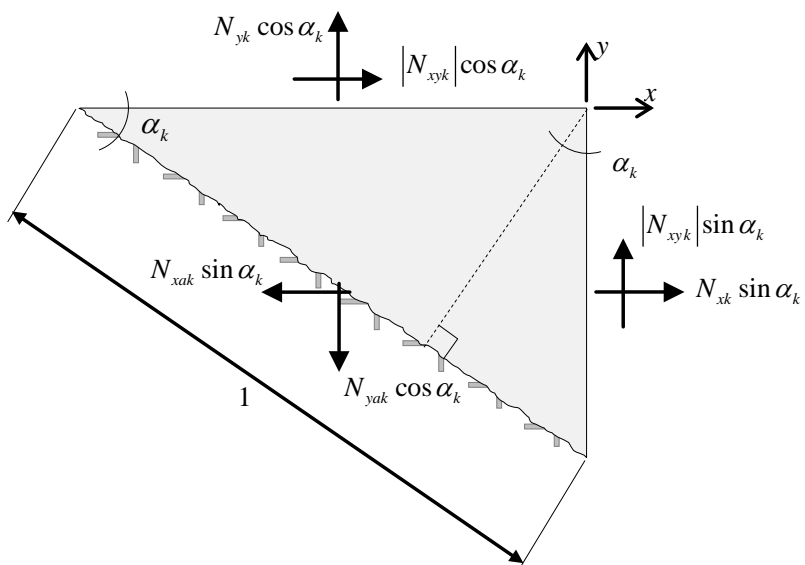

(a)

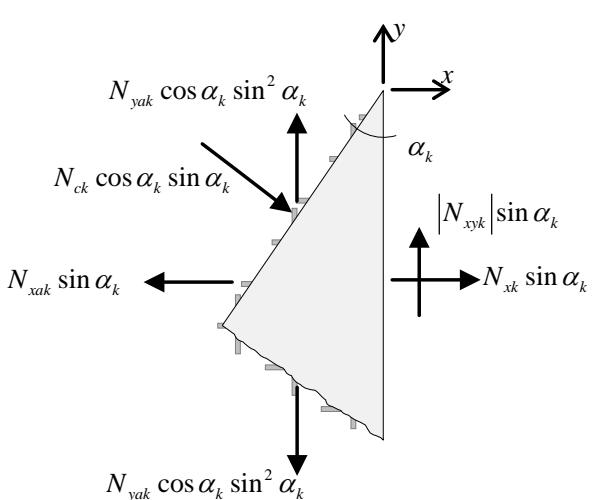

(b)

Fig. 3. Equilibrium of forces in a cracked membrane element: (a) Forces in the reinforcement to equilibrate normal and shear forces; (b) Principal compressive concrete force

The direction of the principal compressive membrane force in the concrete, $N_{c k}$, is parallel to the crack and is, therefore, applied perpendicular to a section as indicated by the dashed line in Fig.

3. (a). The value of the principal compression in concrete Nck is obtained in Eq. (4) from equilibrium in $\mathrm{x}$ direction in Fig. 3. (b) and considering Eq. (2):

$$
N_{x a k} \sin \alpha_{k}=N_{x k} \sin \alpha_{k}+N_{c k} \cos ^{2} \alpha_{k} \sin \alpha_{k} \rightarrow N_{c k}=\left|N_{x y k}\right|\left(\tan \alpha_{k}+\cot \alpha_{k}\right) \mid
$$

There is a variable in the above presented equations, i.e. the crack direction $\alpha_{k}$, that needs to be chosen by the designer. As it's in the designer's interest to find the optimum reinforcement, this variable $\alpha_{k}$ will have a specific value.

If it is assumed that the reinforcement placed at layer $k$ has yielded, the total amount of steel needed will be proportional to the summation of tension forces in the reinforcement in this layer, $N_{\text {total }, k}=N_{x a k}+N_{y a k}$. So, the value of $\alpha_{k}$ that corresponds to the minimum reinforcement can be obtained by partial derivative of the summation of Eqs. (2) and (3): 


$$
\frac{\partial N_{\text {total }, k}}{\partial \alpha_{k}}=0 \rightarrow\left|N_{x y k}\right|\left(-\frac{1}{\sin ^{2} \alpha_{k}}+\frac{1}{\cos ^{2} \alpha_{k}}\right)=0 \rightarrow \sin \alpha_{k}=\cos \alpha_{k} \rightarrow \alpha_{k}=45^{\circ}
$$

Solutions given by Eqs. (2) to (4) are valid if $N_{x a k} \geq 0$ and $N_{y a k} \geq 0$, that is, both $x$ and $y$ reinforcements are subjected to tension forces, in this case $\alpha_{k}=45^{\circ}$ is chosen for the reinforcement design. If this condition is not met, one of the following cases can be found. It is interesting to notice that the classification below has been made based on the limit of applicability of Equations 2 to 4, i.e.: $\alpha_{k}=45^{\circ}$ and $N_{x a k} \leq 0$ and/or $N_{y a k} \leq 0$.

a) If $N_{x k}<-\left|N_{x y k}\right|$ and $N_{y k} \geq-\left|N_{x y k}\right|$, the reinforcement in the $x$ direction is compressed. In this situation $N_{x a k}=0$ - no reinforcement in $x$ direction is required and the crack angle, $\alpha_{k}$, can be obtained from Eq. (2) imposing $N_{x a k}=0$. In this situation, the angle that defines the orientation of the crack in the membrane is given by Eq. (6):

$$
\alpha_{k}=\arctan \left(\frac{\left|N_{x y k}\right|}{-N_{x k}}\right)
$$

b) If $N_{y k}<-\left|N_{x y k}\right|$ and $N_{x k} \geq-\left|N_{x y k}\right|$, the reinforcement in the $y$ direction is compressed. In this situation $N_{y a k}=0$ - no reinforcement in $y$ direction is required and the crack angle, $\alpha_{k}$, can be obtained from Eq. (3) imposing $N_{y a k}=0$. Now, the angle $\alpha_{k}$ can be obtained from Eq. (7):

$$
\alpha_{k}=\arctan \left(\frac{-N_{y k}}{\left|N_{x y k}\right|}\right)
$$

c) If $N_{x k}<-\left|N_{x y k}\right|$ and $N_{y k}<-\left|N_{x y k}\right|$, both reinforcements in the $x$ and $y$ directions are compressed. Therefore, $N_{x a k}=N_{y a k}=0$ - no reinforcement in either $x$ or $y$ direction is 
required - and the maximum compression in concrete can be calculated from the Mohr's circle representation of the tensor of forces $N$ in layer k (Fig. 4). Being:

$$
N_{c k}=\frac{1}{2}\left(N_{x k}+N_{y k}\right)-\frac{1}{2} \sqrt{\left(N_{x k}-N_{y k}\right)^{2}+4 N_{x y k}}
$$

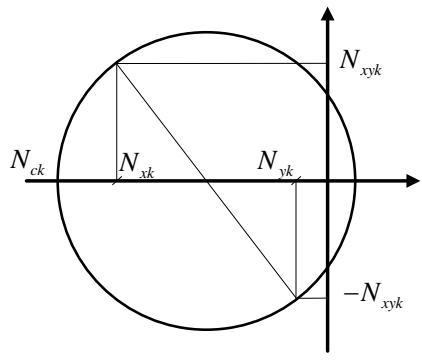

Fig. 4. Mohr's circle of forces for the case Nxk $<-\mid$ Nxyk $\mid$ and Nyk $<-|\mathbf{N x y k}|$.

\section{Concrete compression block}

According to Eq. (1), the membrane forces acting on both top and bottom layers and, consequently, the forces in the concrete strut and in the reinforcement would be completely determined if the geometry of the sandwich shell element were defined, that is, if the values $c_{t}$ and $c_{b}$ are known.

Assuming that the middle surface of one of the layers corresponds to the centroid of the tension reinforcement required for the predominant bending, then, once this net is placed, the thickness of the corresponding layer is known. So, only the thickness of the opposite layer needs to be estimated.

As previously mentioned, the Brondum-Nielsen method [7] considers that the principal compressive force $N_{c k}$ in the concrete is made resistant by a uniformly distributed stress in a depth equal to the thickness of the layer, ck (Eq. (9) and Fig. 5 for the case of the top layer, $k=$ $t$ ). In Eq. (9) $f_{c}$ is the compressive strength of the concrete.

$$
c_{k}=\frac{N_{c k}}{f_{c}}
$$


The former assumption resembles the Whitney's stress block used in the ultimate design of beams.

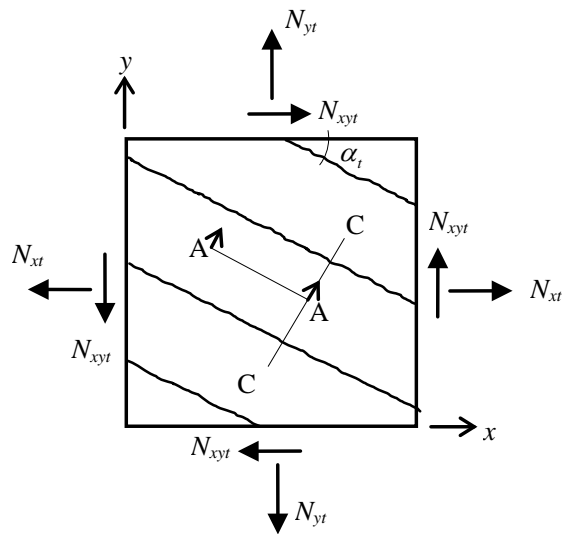

Top face of the shell element

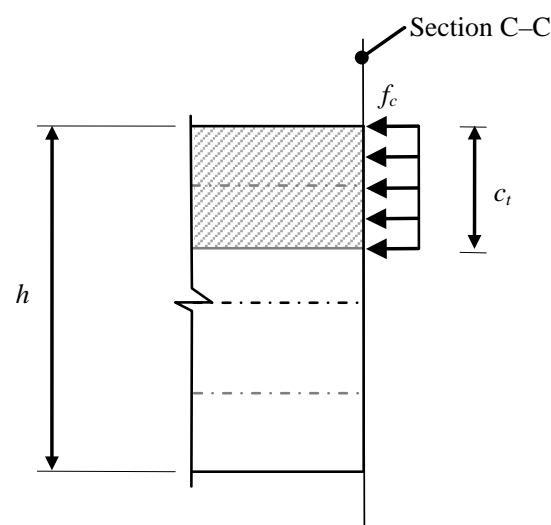

Section A-A

Fig. 5. Compressive stress in top layer

Imagine now that we are dealing with a beam whose cross section is A - A in Fig. 5; and this section is subjected to a bending moment $M$ that comprises the upper part of the cross-section and to a tensile axial force $N$ applied at the centroid of the section (Fig. 6). If moments are taken at the level of the tension reinforcement, the resultant moment $M_{a}$ is:

$M_{a}=M-N e_{j}$

$e_{j}$ being the distance between the centroids of the section and the tension reinforcement in layer j.
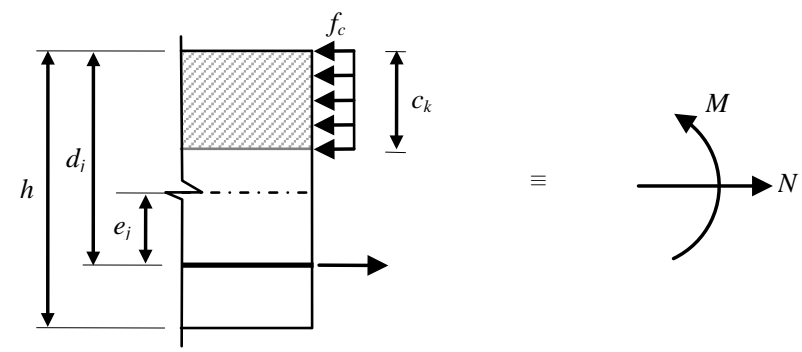

Fig. 6. Combined flexure and axial action in a beam

This moment $M_{a}$ has to be balanced by the compression in the concrete in a depth equal to $c_{k}$. Therefore: 


$$
M_{a}=c_{k} f_{c}\left(d_{j}-\frac{c_{k}}{2}\right)
$$

where $d_{j}$ is the distance between the upper fibre in the cross-section (i.e. the most compressed one) and the level of the tension reinforcement placed in layer $j$ opposite to k (Fig. 6). As indicated above, if the depth of the compression block is to be computed in the top layer, then $k$ $=t$ and $j=b$, and vice versa.

The value of the depth of the compression block, $c_{k}$, is an unknown. Brondum-Nielsen adopts as a first estimation of $c_{k}$ the one obtained from Eq. (11) $M_{a}$ being the one obtained from Eq. (10) where $M$ and $N$ are the predominant bending moment and its corresponding axial force per unit of length, respectively, acting on the slab considered. Although a better approach to trigger the procedure may be obtained by using $\mathrm{M}+|\mathrm{Mxy}|$ instead of $\mathrm{M}$-as used in the RC design of elements to bending plus torsion-, the authors have adopted Brondum-Nielsen's original approach in what follows, see Fig. 7.

\section{The application of the approach}

According to Eq. (1), the geometry of the sandwich element $-c_{t}$ and $c_{b}-$ has to be known to compute the values of the membrane forces $N_{x k}, N_{y k}$ and $N_{x y k}$. At the same time, this geometry depends on those membrane forces - Eq. (9) -. Thus, the problem has to be tackled in an iterative manner.

In all the above stated, it had been assumed that the reinforcement under tension due to the predominant bending is placed in the middle of the layer whereas a first estimation of the thickness of the opposite layer is obtained from Eq. (11). It is important to point out that the reinforcement placement is usually governed by the requirements of concrete cover.

Once the positions of the reinforcement in both layers, and as a result its thicknesses, are known, the external actions $\left(N_{x}, N_{y}, N_{x y}, M_{x}, M_{y}\right.$ and $\left.M_{x y}\right)$ can be resolved into membrane forces 
in the outer layers of the sandwich and the procedure proposed by Brondun-Nielsen [7] can be applied.

Fig. 7 shows a flow chart that explains in detail the entire process proposed by Brondun-Nielsen [7]. If predominant moment $M$ compresses top fiber, then $k=t$ and $j=b$. On the other hand, if the bottom layer is compressed by $M$, then $k=b$ and $j=t$.

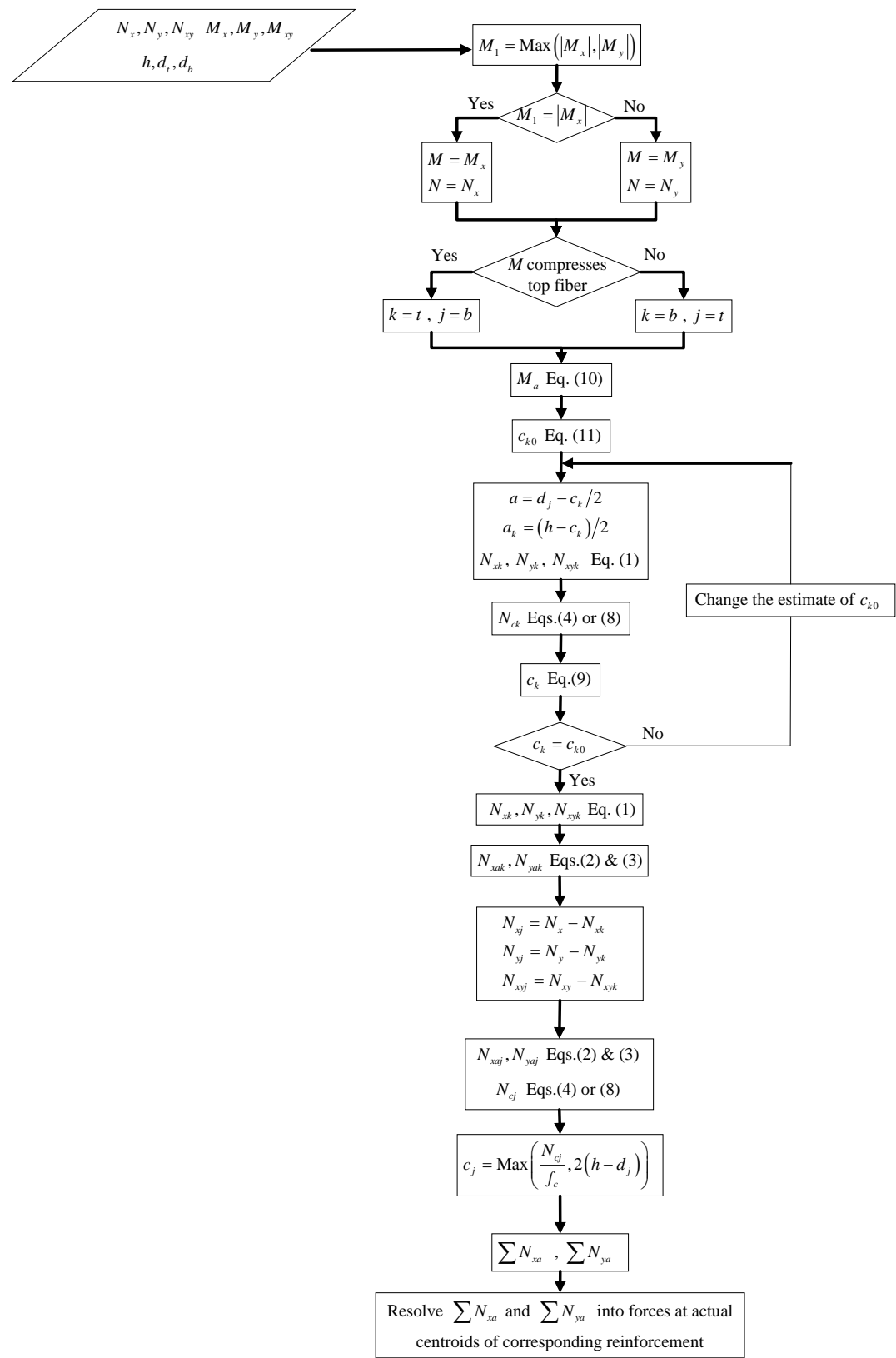

Fig. 7. Flow chart detailing the Brondum-Nielsen approach

After the whole process has been completed, once the geometry of both layers is known and forces in the reinforcements of both outer layers have been obtained from Eqs. (2) and (3), it is 
necessary to resolve the forces at the centroids of the actual levels of the reinforcements if they have not already been computed at those levels.

\section{Plane strain distribution for ultimate state of $\mathrm{RC}$ slabs in bending}

Once the tension forces in both $x$ and $y$ reinforcement $-N_{x a t}, N_{y a t}, N_{x a b}, N_{x a b}$ - have been calculated from Eqs. (2) and (3), it is necessary to compute the required areas of steel to withstand these tension forces in both directions $-x$ and $y$ - and in both layers - top and bottom

In the example given in Brondum-Nielsen's work [7] these areas are computed by dividing the obtained tension forces $-N_{x a}$ and $N_{y a}$ - by the prescribed steel design strength, taken as the steel yield stress, $f_{y}$. However, this procedure can be reconsidered because the actual state of steel stress should depend on the compression block depth, as it occurs in the ultimate design of beams.

Back to the shell element case, assuming that Kirchhoff's hypothesis of plane sections is satisfied, it is evident from comparison with the beam case that the tensile stress in the reinforcement cannot always be considered equal to $f_{y}$ without paying attention to the value of $C_{k}$.

The beam section shown in Fig. 6 is now subjected to the bending moment $M$ and the axial force N, as presented in Fig. 8. Satisfying the plane sections hypothesis, if the applied actions cause a top fibre strain equal to concrete ultimate compression strain, $\varepsilon_{c u}$, and a strain at level of tensile reinforcement equal to steel yield strain, $\varepsilon_{y}$, then the section is said be in balance conditions, [21][22]. At this point, the compression block depth is $c_{k l i m}$ and the distance from the uppermost fibre of the cross section to the neutral fibre is $\chi_{\text {klim. }}$. Both values are related by a coefficient $\lambda$ taken as 0,8 according to EC2 [4] for $f_{c} \leq 50 \mathrm{MPa}$. In the case of ultimate limit state of bending if the neutral fibre depth becomes greater than $\chi_{\text {klim }}$ the strain at reinforcement level is lower than $\varepsilon_{y}$ and, consequently, the steel stress is lower than $f_{y}$. 


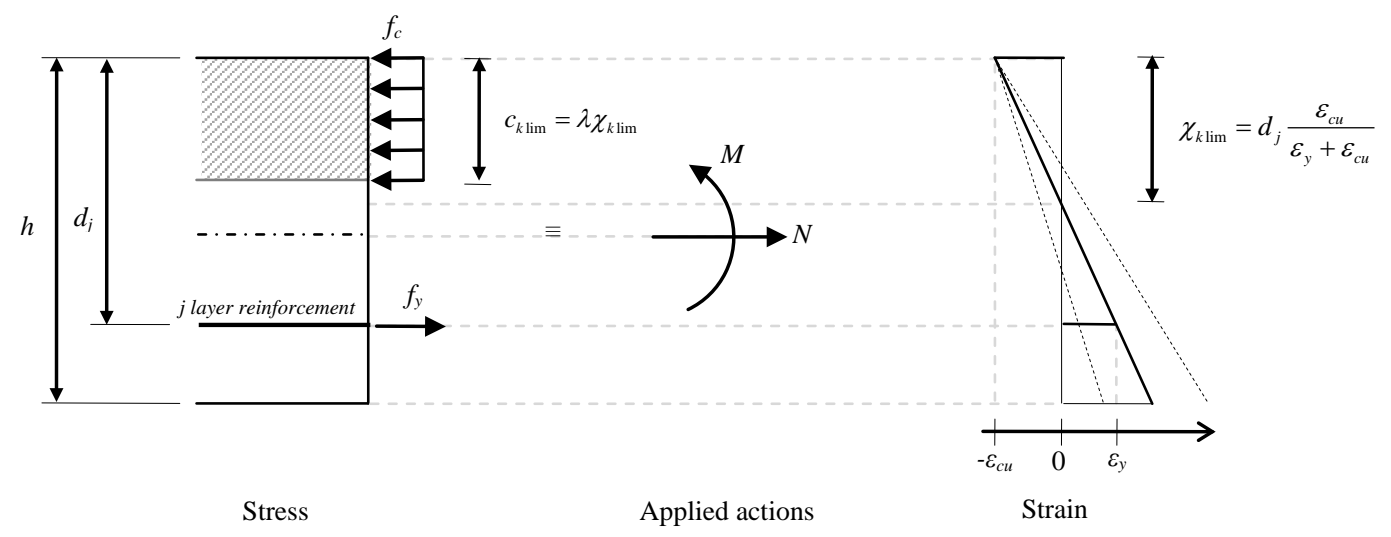

Fig. 8. Combined flexure and axial action in a beam: balance point determination

If the cross section given in Fig. 8 corresponded to a RC shell element and it were positioned parallel to the direction of the principal compressive stress in the concrete (section A-A in Fig. 5), the compression block in one layer would lead to the yielding of the reinforcement in the opposite layer just under some circumstances as outlined below.

In the beam represented in Fig. 8, the direction of the reinforcement coincides with the direction of the compressive force in concrete. In this case, the depth of the compression block, $c_{k \text { lim, }}$ corresponding to the balance point can be obtained from the expression:

$$
c_{k \lim }=\lambda \cdot d_{j} \frac{\varepsilon_{c u}}{\varepsilon_{y}+\varepsilon_{c u}}
$$

In the case of RC slabs, the orientation of the principal compressive force in the concrete in the outer layer $k, \alpha_{k}$, does not generally coincide with the orientation of the reinforcement ( $x$ and $y$ directions, respectively) in the opposite outer layer $j$, as presented in Fig. 9(a).

The hypotheses of the plane strain distribution for ultimate design of RC slabs in bending and torsion are:

1. Ultimate strength of RC slabs in bending and torsion with or without axial force behaves in accordance with an ultimate plane strain distribution.

2. The orientation of the ultimate plane strain distribution in the plane of the slab is defined by the principal direction of compression in concrete. 
Since both hypotheses are to be used in a design process, the Upper Bound Theorem of plasticity guaranties that the forces obtained using these hypotheses are an upper value of the true collapse forces.

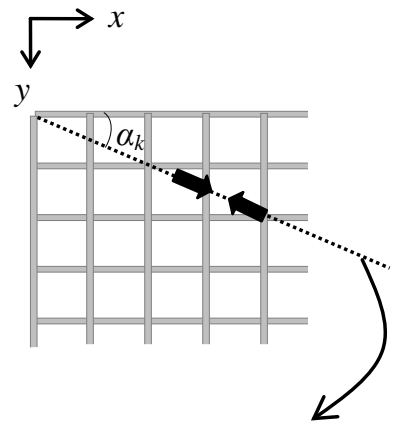

Direction of the principal compressive force in concrete in layer $k$ opposite to $j$

(a)

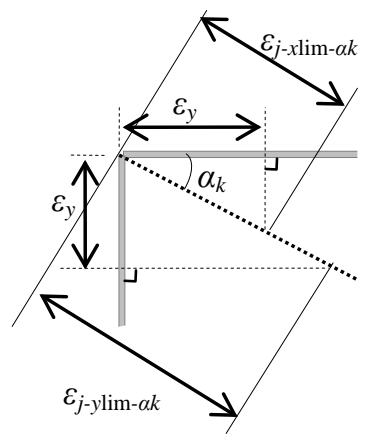

(b)

Fig. 9. Strain decomposition

Stress-strain models of concrete and steel in ultimate strength design have to comply with those approved by Standards such as Eurocode 2 or ACI-318.

In line with both hypotheses, if a sandwich model is used, such as Brondum-Nielsen's [7] or Marti's [9], the principal compressive direction in one layer coincides with the principal tensile strain direction in the opposite one, as shown in Fig. 9(a) and 9(b). According to the second hypothesis, the principal direction is given by the principal compressive direction in the compressed layer $(k)$. Therefore yielding of the steel placed in layer $j$ and in each direction $x$ or $y$ of reinforcement corresponds to a yielding strain in the direction of the crack of the opposite layer $\alpha_{k}$ given by (Fig. 9(b)):

$$
\begin{aligned}
& \varepsilon_{j-x \lim -\alpha k}=\frac{\varepsilon_{y}}{\cos \alpha_{k}} \\
& \varepsilon_{j-y \lim -\alpha k}=\frac{\varepsilon_{y}}{\sin \alpha_{k}}
\end{aligned}
$$

The maximum value of the thickness of layer $k$ for which the yielding of the steel placed in the opposite layer $j$ occurs, can be obtained from: 
$C_{k i \lim }=\lambda \cdot d_{j i} \cdot \frac{\varepsilon_{c u}}{\varepsilon_{j-i \lim -\alpha k}+\varepsilon_{c u}}$

$d_{j i}$ being the position of the reinforcement in $i$ direction ( $i=x$ or $y$ ) placed in the $j$ layer opposite the compressed layer $\mathrm{k}$ with respect to the furthest fibre of the cross section, as indicated in Fig. 10.

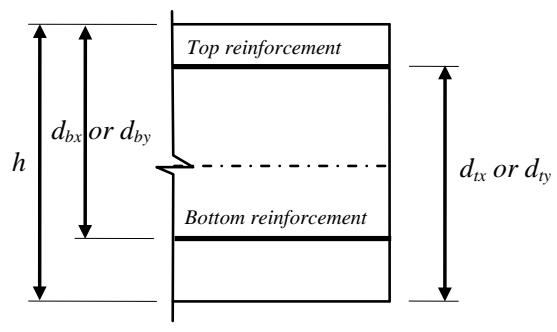

\section{Fig. 10. Nomenclature}

Once $c_{k i l i m}$ is known (i.e. $c_{k x l i m}$ and $c_{k y l i m}$ ), the designer has to compare the obtained value of $c_{k}$ from the Brondum-Nielsen's approach with $c_{k x l i m}$ and $c_{k y l i m}$. If $c_{k}$ is lower than the minimum $c_{k i l i m}$ then the stress in the tension reinforcement in $i$ direction in the opposite layer $j$ can be considered $f_{y}$. On the contrary, the geometry in the slab has to be altered in order to achieve the yielding of the reinforcement or if the stress of the reinforcement is smaller than $f_{y}$ and has to be calculated.

\section{Example 1}

The example presented in the work of Brondum-Nielsen [7] is explained here again in order to check if the compression blocks in both outer layers are deep enough to guarantee that the tensile stress in the reinforcement is the yield stress, fy. Fig. 11 shows a section of the slab studied in [7], the actions acting on it and the material properties.

The example helps to clarify why the new hypotheses are needed. Fig. 12 shows the $1 \times 1 \mathrm{~m}$ slab of the example with the external forces and moments depicted. The signs are indicated by the directions of the arrows so the companion numbers only indicate the absolute value of the forces and moments. If the axial forces $N_{x}$ and $N_{y}$ were of little importance, clearly the moment $M_{x}$ (-83 
$k N \cdot m$ ) would command the behaviour of the slab. In this case we can deduce that in the top layer the steel in the $\mathrm{x}$-direction can be considered at $f_{y}$ while the steel in the y-direction will barely be at $f_{y}$.

All the measurements in mm

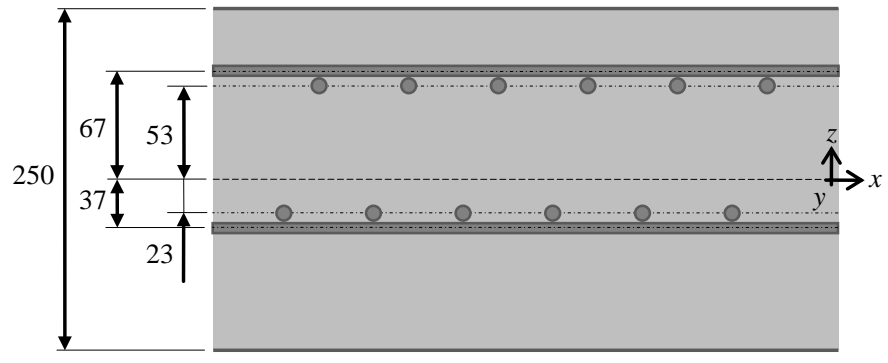

Actions

$N_{x}=-120000 \mathrm{~N} / \mathrm{m}$

$N_{y}=300000 \mathrm{~N} / \mathrm{m}$

$N_{x y}=170000 \mathrm{~N} / \mathrm{m}$

$M_{x}=-83000 \mathrm{~N} \mathrm{~m} / \mathrm{m}$

$M_{y}=12000 \mathrm{~N} \mathrm{~m} / \mathrm{m}$

$M_{x y}=800 \mathrm{~N} \mathrm{~m} / \mathrm{m}$

Materials properties

$f_{c}=7 \mathrm{~N} / \mathrm{mm}^{2}$

$\varepsilon_{c u}=3.50 \%$

$f_{y}=270 \mathrm{~N} / \mathrm{mm}^{2}$

$E_{\mathrm{s}}=200000 \mathrm{~N} / \mathrm{mm}^{2}$

$\varepsilon_{y}=1.35 \%$

Fig. 11. Section of the slab studied by Brondum-Nielsen and external loads. Adapted from [7]

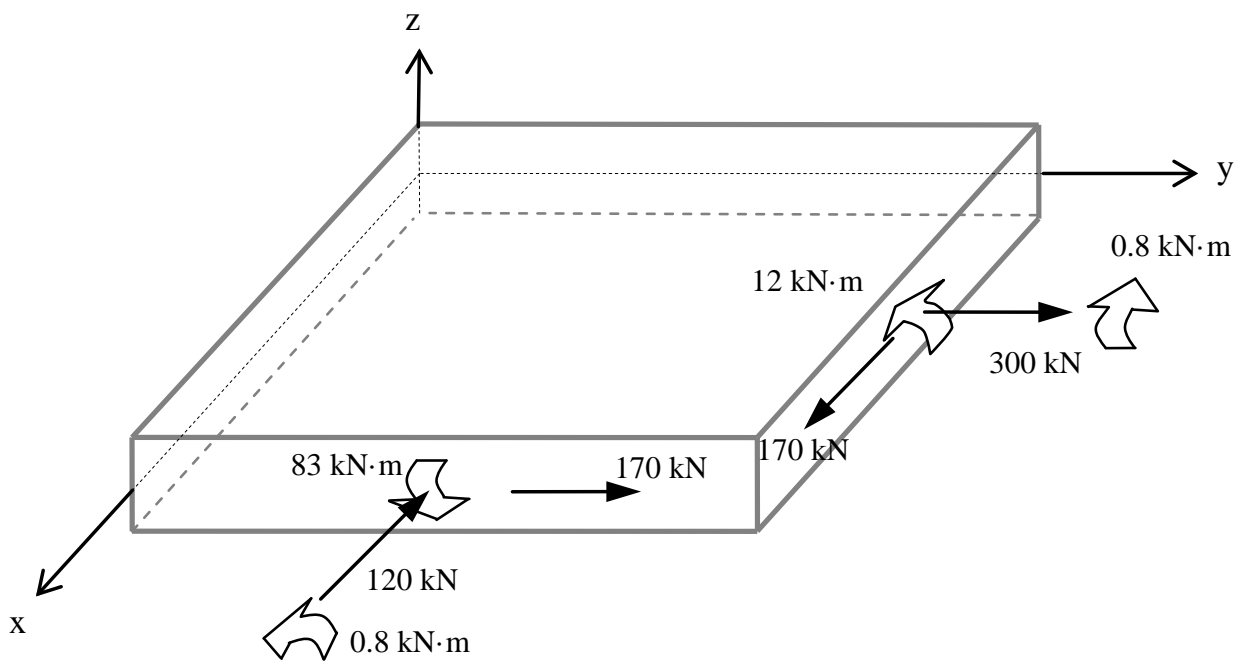

Fig. 12. Orientation of the external actions on the slab.

The problem is solved following the flow chart given in Fig. 7. According to it, Mx is the predominant bending moment and it compresses the bottom fiber so $k=b$ and $j=t . M_{a}$ obtained from Eq. (10) is:

$M_{a}=83000-67\left(\frac{-120000}{1000}\right)=91040 \mathrm{~N} \cdot \mathrm{mm} / \mathrm{mm}$ 
The first estimation of the thickness of the compressed layer, $c_{b 0}$, is obtained from Eq. (11) with $d_{j}=d_{t}=192 \mathrm{~mm}$ (distance between the lowermost fibre of the cross section and the centroid of $x$ reinforcement in the top layer), that is: $c_{b 0}=87,82 \mathrm{~mm}$.

For this first estimation of $c_{b}, c_{b 0}$, the membrane forces in the bottom layer are obtained from Eq.(1):

$$
\begin{aligned}
& a=192-\frac{87.82}{2}=148.09 \mathrm{~mm} \\
& a_{b}=\frac{250-87.82}{2}=81.09 \mathrm{~mm} \\
& N_{x b}=-120 \frac{148.09-81.09}{148.09}+\frac{-83000}{148.09}=-614.76 \mathrm{~N} / \mathrm{mm} \\
& N_{y b}=300 \frac{148.09-81.09}{148.09}+\frac{12000}{148.09}=216.76 \mathrm{~N} / \mathrm{mm} \\
& N_{x y b}=170 \frac{148.09-81.09}{148.09}+\frac{800}{148.09}=82.31 \mathrm{~N} / \mathrm{mm}
\end{aligned}
$$

Since $N_{x b}<-\left|N_{x y b}\right|$ and $N_{y b} \geq-\left|N_{x y b}\right|$ no reinforcement is needed in $x$ direction in the bottom layer.

The crack angle in this layer is obtained from Eq. (6):

$$
\alpha_{b}=\arctan \left(\frac{82.31}{614.76}\right)=7.63^{\circ}
$$

The principal compression force on the concrete in the bottom layer is:

$$
N_{c b}=82.31\left[\tan \left(7.63^{\circ}\right)+\cot \left(7.63^{\circ}\right)\right]=625.78 \mathrm{~N} / \mathrm{mm}
$$

Because $c_{b}=N_{c b} / f_{c}=89.40 \mathrm{~mm}$ is deeper than the first estimation $-c_{b 0}-$, a value of $c_{b}$ equal to 90 $\mathrm{mm}$ is adopted and the former values recalculated.

$$
\begin{aligned}
& N_{x b}=-619.37 \mathrm{~N} / \mathrm{mm} \\
& N_{y b}=218.38 \mathrm{~N} / \mathrm{mm} \\
& N_{x y b}=82.93 \mathrm{~N} / \mathrm{mm}
\end{aligned}
$$


In the bottom layer only reinforcement in y direction is required; the tension force on it is obtained from Eq. (3) as:

$$
N_{y a b}=229.47 \mathrm{~N} / \mathrm{mm}
$$

Assuming that the middle surface of the top layer coincides with the centroid of $x$ reinforcement, the depth of this layer can be obtained:

$$
C_{t}=2(250-192)=116 \mathrm{~mm}
$$

The values of the membrane forces acting upon it can be computed from Eq. (1):

$$
\begin{aligned}
& N_{x t}=499.32 \mathrm{~N} / \mathrm{mm} \\
& N_{y t}=81.63 \mathrm{~N} / \mathrm{mm} \\
& N_{x y t}=87.07 \mathrm{~N} / \mathrm{mm}
\end{aligned}
$$

Since $N_{x t} \geq-\left|N_{x y t}\right|$ and $N_{y t} \geq-\left|N_{x y t}\right|$, then both $x$ and $y$ reinforcements are required in the top layer. The crack angle at this layer is $45^{\circ}$ and the values of the tensile forces in $x$ and $y$ directions and the principal compression force in the concrete for the top layer are obtained from Eqs. (2) to (4) as:

$$
\begin{aligned}
& N_{x a t}=586.39 \mathrm{~N} / \mathrm{mm} \\
& N_{\text {yat }}=168.71 \mathrm{~N} / \mathrm{mm} \\
& N_{c t}=174.16 \mathrm{~N} / \mathrm{mm}
\end{aligned}
$$

It is verified that the corresponding principal compressive stress in the concrete is lower than $f_{c}$ :

$$
\frac{N_{c t}}{C_{t}}=\frac{174.16}{116}=1.50 \mathrm{~N} / \mathrm{mm}^{2}<7 \mathrm{~N} / \mathrm{mm}^{2}
$$

The next step is to relocate the tension forces of the reinforcement in both top and bottom layers. The resultant in $x$ direction does not need to be computed since $x$ reinforcement is not required in the bottom layer and the middle surface of the top layer coincides with the centroid 
of $x$ reinforcement in this layer. Therefore, it is only necessary to calculate the resultant of tension forces in the $y$ direction of reinforcement.

$$
\sum N_{y a}=398.18 \mathrm{~N} / \mathrm{mm}
$$

If $z=0$ is placed on the middle surface of the shell element (Fig. 11), the $z$ coordinate of the point of application of $\sum N_{y a}$ is:

$$
z_{y a}=\frac{N_{y a t} Z_{y a t}+N_{y a b} Z_{y a b}}{\sum N_{y a}}=\frac{168.71 \cdot 67+229.47(-80)}{398.18}=-17.72 \mathrm{~mm}
$$

The actual positions of $y$ reinforcement in top and bottom layer are $z^{*}{ }_{\text {yat }}=53 \mathrm{~mm}$ and $Z_{\text {yab }}^{*}=-23 \mathrm{~mm}$, the corresponding tension forces at those levels, $N_{y a t}^{*}$ and $N_{y a b}^{*}$, can be obtained from:

$$
\begin{aligned}
& N^{*}{ }_{y a t}=\sum N_{y a} \frac{Z_{y a}-Z^{*}{ }_{y a b}^{*}}{Z_{\text {yat }}^{*}-Z^{*}{ }_{y a b}}=398.18 \frac{-17.72+23}{53+23}=27.68 \mathrm{~N} / \mathrm{mm}
\end{aligned}
$$

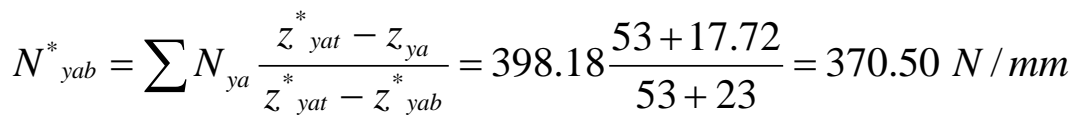

Once the tensile forces in reinforcement have been determined, the necessary area of steel is obtained dividing by $f_{y}$ :

$$
\begin{aligned}
& A_{t x}=2.17 \mathrm{~mm}^{2} / \mathrm{mm} \\
& A_{t y}=0.10 \mathrm{~mm}^{2} / \mathrm{mm} \\
& A_{b y}=1.37 \mathrm{~mm}^{2} / \mathrm{mm}
\end{aligned}
$$

The Brondum-Nielsen procedure ends here. According to the hypothesis discussed in this paper, it has to be verified that the steel has yielded, in the case that it has not, a different stress value must be considered. 


\section{The proposed procedure}

In order to verify that reinforcement has yielded, the proposed methodology is applied. For the bottom layer, the angle of inclination of the cracks -i.e. the orientation of the principal compressive stress in concrete- is $\alpha_{b}=7.63^{\circ}$. In the top layer both $x$ and $y$ reinforcements are required, their yielding strains and their corresponding maximum thickness in the opposite layer are -equations 13 and 14 respectively-:

- For $x$ reinforcement:

$$
\begin{aligned}
& \varepsilon_{t-x \lim -\alpha b}=\frac{\varepsilon_{y}}{\cos 7.63^{\circ}}=\frac{0.00135}{\cos 7.63^{\circ}}=0.00136 \\
& c_{b x \lim }=\lambda \cdot d_{t x} \frac{\varepsilon_{c u}}{\varepsilon_{t-x \lim -\alpha b}+\varepsilon_{c u}}=0.8 \cdot 192 \frac{0.0035}{0.00136+0.0035}=110.62 \mathrm{~mm}
\end{aligned}
$$

- For $y$ reinforcement:

$$
\begin{aligned}
& \varepsilon_{t-y \lim -\alpha b}=\frac{\varepsilon_{y}}{\sin 7.63^{\circ}}=0.010 \\
& C_{b y \lim }=\lambda \cdot d_{t y} \frac{\varepsilon_{c u}}{\varepsilon_{t-y \lim -\alpha b}+\varepsilon_{c u}}=0.8 \cdot 178 \frac{0.0035}{0.010+0.0035}=36.45 \mathrm{~mm}
\end{aligned}
$$

From comparison of the thickness of the bottom layer $\left(c_{b}=90 \mathrm{~mm}\right)$ with $c_{b x l i m}$ and $c_{b y l i m}$ it is clear that $x$ reinforcement in the top layer is yielded but not, however, the $y$ reinforcement. It was deduced in light of Fig. 12 and commented at the beginning of the example. The area of steel in $x$ direction per unit of length can be obtained as:

$$
A_{t x}=\frac{N_{x a t}}{f_{y}}=\frac{586.39 \mathrm{~N} / \mathrm{mm}^{2}}{270 \mathrm{~N} / \mathrm{mm}^{2}}=2.17 \mathrm{~mm}^{2} / \mathrm{mm}
$$

According to the hypotheses considered in the paper, for $c_{b}=90 \mathrm{~mm}$ steel in $y$ direction is in the elastic domain and its strain and stress are: 


$$
\begin{aligned}
& \varepsilon_{t-y}=\frac{d_{t y}-c_{b} / 0.8}{c_{b} / 0.8} \varepsilon_{c u} \sin \alpha_{b}=\frac{178-90 / 0.8}{90 / 0.8} 0.0035 \sin 7.63^{\circ}=0.00027 \\
& \sigma_{t-y}=E_{s} \cdot \varepsilon_{t-y}=53.98 \mathrm{MPa}
\end{aligned}
$$

The required area of steel in $y$ direction per unit of length is:

$$
A_{t y}=\frac{N^{*}{ }_{\text {yat }}}{\sigma_{t-y}}=\frac{27.68 \mathrm{~N} / \mathrm{mm}}{53.98 \mathrm{~N} / \mathrm{mm}^{2}}=0.513 \mathrm{~mm}^{2} / \mathrm{mm}
$$

In the case of steel in the bottom layer, the orientation of the strain plane is defined by the principal direction of compression in the top layer. For the top layer, $\alpha_{t}=45^{\circ}$. In the bottom layer only $y$ reinforcement is required so the strain in the principal tensile direction is given by:

$$
\varepsilon_{b-y \lim -\alpha t}=\frac{\varepsilon_{y}}{\sin 45^{\circ}}=0.0019
$$

If the compression block depth obtained as $c^{*}{ }_{t}=N_{c t} / f_{c}=24.9 \mathrm{~mm}$ is considered for the top layer, as represented in Fig. 13(b), the maximum value of the compression block depth for which the $y$ reinforcement yields can be obtained from Eq. (14) would be:

$$
c_{t y \lim }=\lambda \cdot d_{b y} \frac{\varepsilon_{c u}}{\varepsilon_{b-y \lim -\alpha t}+\varepsilon_{c u}}=0.8 \cdot 148 \frac{0.0035}{0.0019+0.0035}=76.61 \mathrm{~mm}
$$

This approach is safe because membrane forces were supposed to act with a smaller lever arm with respect to the lower reinforcement as Fig. 13 shows, so the calculated membrane forces are greater than the actual ones.

Because $c^{*}{ }_{t}=24.9 \mathrm{~mm}<c_{\text {tylim }}=76.61 \mathrm{~mm}$ the $y$ reinforcement in the bottom layer yields and therefore, the corresponding area of steel can be obtained dividing the tensile force between $f_{y}$ :

$$
A_{b y}=\frac{N^{*}{ }_{y a b}}{f_{y}}=\frac{370.50 \mathrm{~N} / \mathrm{mm}}{270 \mathrm{~N} / \mathrm{mm}^{2}}=1.37 \mathrm{~mm}^{2} / \mathrm{mm}
$$


An alternative, in order to force the yielding of the $y$ reinforcement in the top layer, is to change the geometry of the layers. This modification of the geometry may involve increasing the thickness of the slab and/or relocating the reinforcement.

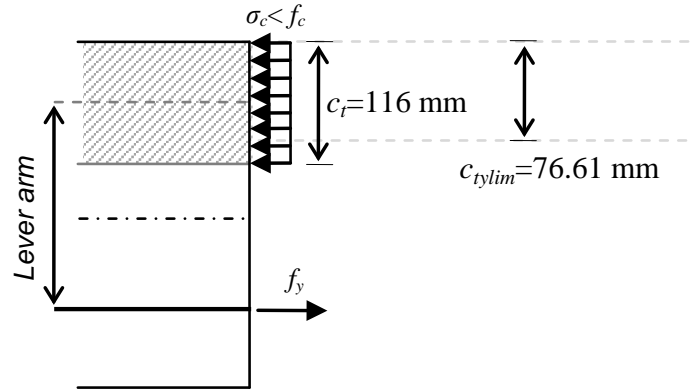

(a)

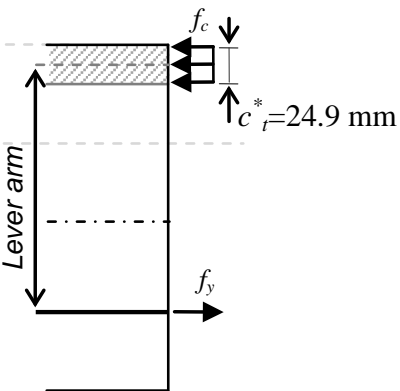

(b)

Fig. 13. Compression block for the upper layer. Comparison between the resulting depth (a) assuming that level of top reinforcement is the middle surface of the layer and (b) the resulting depth applying Eq. (9)

\section{Example 2}

The previous slab is modified as indicated in Fig. 14, in this case all the reinforcement yield, i.e. the required cross-sectional areas of reinforcement per unit of length can be obtained dividing the tensile forces between $f_{y}$. These required areas of reinforcement are summarized in Fig. 14 .

All the measurements in mm

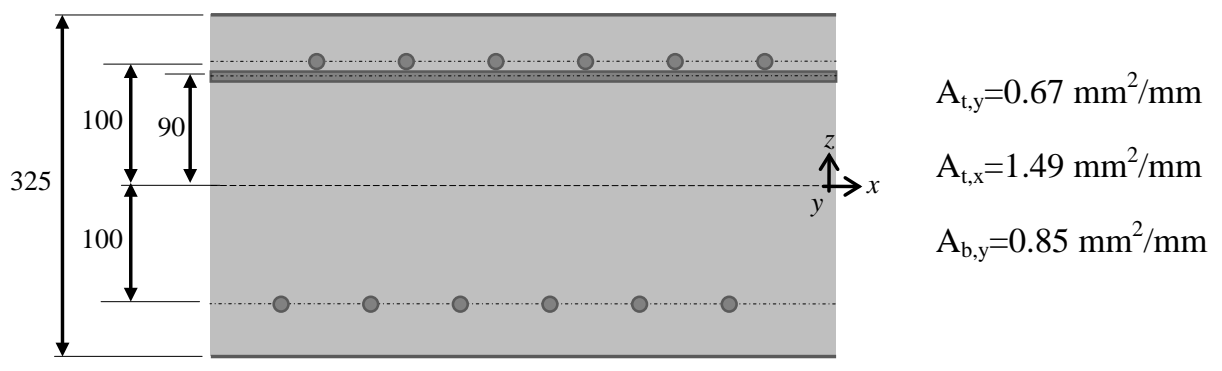

Fig. 14. Modified slab of the example of Brondum-Nielsen and required areas of reinforcement per unit of length

A detailed study of the stress of the top reinforcement in y-direction $\left(\sigma_{\mathrm{ty}}\right)$ relative to the thickness of the slab and the position of the steel for the same external loading as those considered in the previous example are shown in Fig. 15. The example of Fig. 14 can be observed in Fig. 15, if the thickness of the slab is reduced or if the lever arm of the $y$ reinforcement of the top layer is reduced then the steel will not yield. The line of thickness equal 
to $250 \mathrm{~mm}$ and with the geometry of the slab considered in example 1 is also shown, this line contains the case analyzed in the example 1.

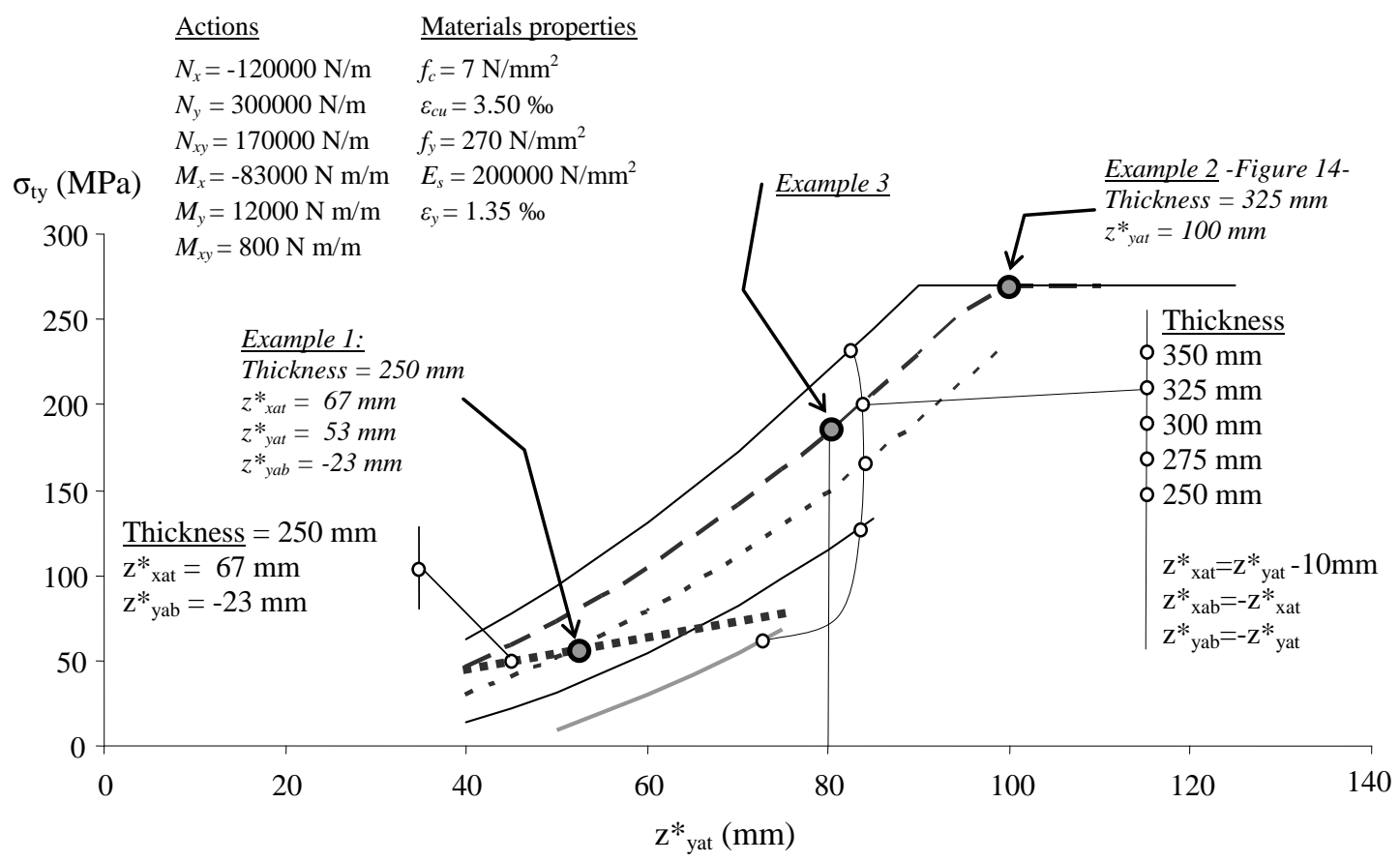

Fig. 15. Stress in the reinforcement in the $y$-direction of the top layer of the slab as function of the location of the reinforcement for several thicknesses.

\section{Example 3}

Fig. 16 shows the values corresponding to strength design of one slab as function of the flexural moment, $M_{y}$. The geometry of the slab is defined by, thickness=325 mm, $\mathrm{z}_{\mathrm{yat}}=80 \mathrm{~mm}$, and is represented in Figure 15 with the label Example 3. It is made with concrete $f_{c}=7 \mathrm{MPa}$ and steel $f_{y}=270 \mathrm{MPa}$.

Beside $M_{y}$, which is considered as variable, the rest of forces and moments acting on the slab are kept constants:

$N_{x}=-120000 \mathrm{~N} / \mathrm{m}, N_{y}=300000 \mathrm{~N} / \mathrm{m}, N_{x y}=170000 \mathrm{~N} / \mathrm{m}, M_{x}=-83000 \mathrm{Nm} / \mathrm{m}$ and $M_{x y}=800 \mathrm{Nm} / \mathrm{m}$.

As is observed in Fig. 15 and in Fig.16 the y-reinforcement in the top layer is not yielded for the value of $M_{y}$ considered in the previous example $\left(M_{y}=12000 \mathrm{Nm} / \mathrm{m}\right)$. 
Fig. 16 (a) represents stresses in the reinforcement in the y-direction for both top and bottom layers, (b) the tension forces in the y-reinforcement for both top and bottom layers, (c) the angle of the crack with respect to the x-direction for both top and bottom layers and (d) the depth of the bottom layer.

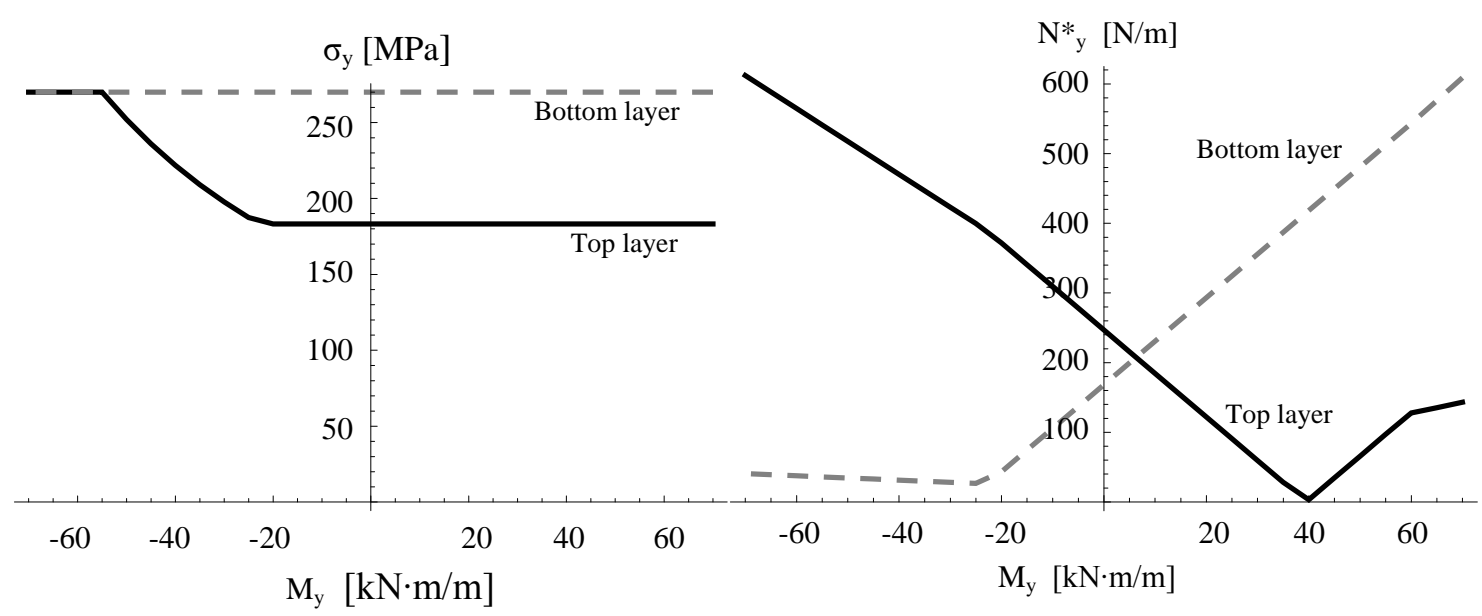

(a)

(b)

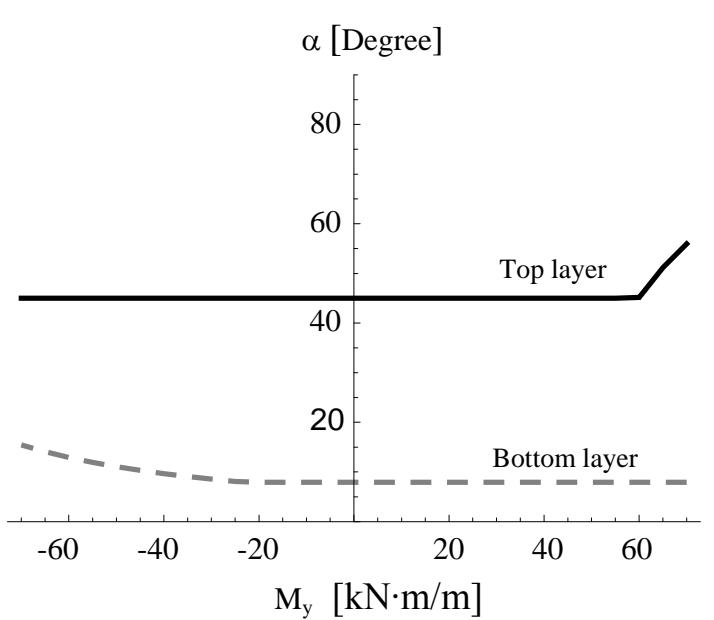

(c)

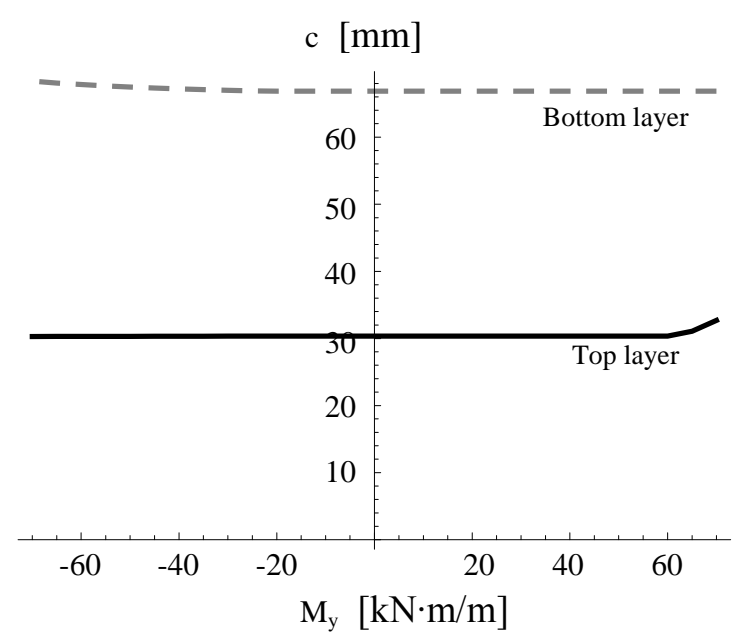

(d)

Fig. 16. Example 3.

Fig. 17 represents the areas of steel as $M_{y}$ increases, as can be observed as $M_{y}$ increases bottom steel in y-direction increases and the upper steel in y-direction decreases. 


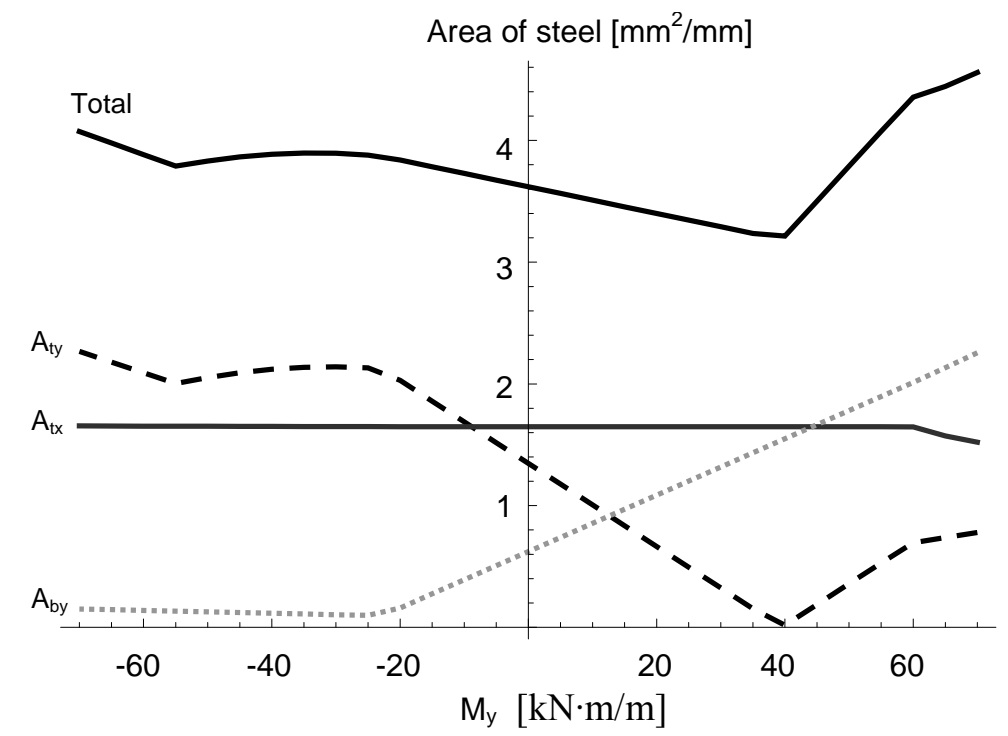

Fig. 17. Steel areas

\section{Conclusions}

The Sandwich element analogy is the most relevant hypothesis used in the bending ultimate limit design of shells and slabs. Once the geometry of the outer layers and the membrane forces acting on them are determined, the tension forces in the reinforcement and the principal compressive force in the concrete can easily be obtained from equilibrium conditions. Finally, Brondum-Nielsen's work [7] aims to compute the necessary amount of reinforcing steel per unit length dividing these tension forces by the steel yield stress, $f_{y}$.

In the present work, the Brondum-Nielsen approach has been summarized in detail and it has been shown that this procedure needs to be applied under some restrictions since reinforcement yielding cannot always be guaranteed. Taking as reference the determination of the balance point concept widely used in beams and columns, a procedure has been developed in order to determine the limits of application of Brondum-Nielsen's method. If these limits are exceeded, either the geometry of the slab or the reinforcement stresses and areas need to be modified. 


\section{Acknowledgements}

The present work was financed by the Spanish Ministry of Education. The second author is a Spanish Government $\mathrm{PhD}$ fellow (FPU grant AP 2010-3707). This support is gratefully acknowledged.

\section{References}

[1] Schladitz F, Frenzel M, Ehlig D, Curbach M. Bending load capacity of reinforced concrete slabs strengthened with textile reinforced concrete. Engineering Structures 2012; 40: 31710

[2] Smith ST, Hu S, Kim SJ, Seracino R. FRP-strengthened RC slabs anchored with FRP anchors. Engineering Structures 2011; 33(4): 1075-13

[3] Jia, X. Revisiting the failure mode of a RC hyperbolic cooling tower, considering changes of material and geometric properties. Engineering Structures 2013; 47: 148-7

[4] EC 2. Eurocode 2: Design of concrete structures_Part 1-1: General rules and rules for buildings EN 1992-1-1. Brussels: European Committee for Standarization, 2004.

[5] ACI Committee 318. Building code requirements for structural concrete (ACI 318-08). Farmington Hills (MI): American Concrete Institute; 2008

[6] FIB. Model Code 2010. Model Code 2010 - Final draft, Volume 1. Fib Bulletin No. 65. Lausanne: International Federation for Structural Concrete; 2012

[7] Broundum-Nielsen T. Optimum Design of Reinforced Concrete Shells and Slabs. Report No R44. Copenhagen: Structural Research Laboratory, University of Denmark; 1974

[8] Gupta AK. Combined membrane and flexural reinforcement in plates and shells. ASCE Journal of Structural Division 1986; 112(3): 550-7 
[9] Marti P. Design of Concrete Slabs for Transerse Shear. ACI Structural Journal, V.87, No2, March-April 1990.

[10] Lourenço PB, Figuerias JA. Automatic design of reinforcement in concrete plates and shells. Engineering Computations 1993; 10(6): 519-23

[11] Lourenço PB, Figueiras JA. Solution for the design of reinforcement concrete plates and shells. Journal of Structural Engineering ASCE 1995; 121(5): 815-9

[12] Fall D, Lundgren K, Rempling R, Gylltof K. Reinforcing tailor-made concrete structures: alternatives and challenges. Engineering Structures 2012; 44: 372-7

[13] Min CS. Design and ultimate behaviour of RC plates and shells. Nuclear Engineering and Design 2004; 228: 207-17

[14] Min CS, Gupta AK. A study of inelastic behaviour of reinforced concrete shells using supercomputers. Technical Report. Raileigh (NC): North Carolina State University; 1992

[15] Min CS, Gupta AK. Vector algorithm for layered reinforced concrete shell element stiffness matrix. Structural Engineering and Mechanics 1995; 3(2): 172-12

[16] Min CS, Gupta AK. Inelastic vector finite element analysis of RC shells. Structural Engineering and Mechanics 1996; 4(2): 139-10

[17] Mahmoud BEH, Gupta AK. Inelastic large displacement behaviour and buckling of hyperbolic cooling tower shells. Technical Report. Raileigh (NC): North Carolina State University; 1993

[18] Tomás A, Martí P. Design of reinforcement for concrete co-planar shell structures using optimization techniques. Meccanica 2010; 45: 657-13

[19] Bertagnoli G, Giordano L, Mancini S. Design and optimization of skew reinforcement in concrete shells. Structural Concrete 2012; 13(4): 248-11 
[20] https://wiki.csiberkeley.com/display/kb/Shell+reinforcement+design

[21] Hernández-Montes E, Gil-Martín LM, Pasadas M, Aschheim M. "Theorem of Optimal Section Reinforcement”. Structural and Multidisciplinary Optimization 2008; 36(5): 50913

[22] Aschheim M, Hernández-Montes E, Gil-Martín LM. “Optimal Domains for Strength Design of Rectangular Sections for Axial Load and Moment according to Eurocode 2”. Engineering Structures 2007; 29(8): 1752-9 